Pre-proof version. Manuscript accepted for publication in Discourse \& Society.

\title{
'Riots Engulfed the City': An Experimental Study Investigating the Legitimating Effects of Fire Metaphors in Discourses of Disorder
}

Christopher Hart (Lancaster University)

c.hart@lancaster.ac.uk

\begin{abstract}
In Cognitive Linguistic Critical Discourse Studies (CL-CDS), metaphor is identified as a key index of ideology and an important device in the legitimation of social action. From this perspective, metaphor is a cognitive-semiotic operation, invoked by metaphorical expressions in discourse, in which a source frame is mobilised to provide a template for sense-making inside a target frame, leading to particular framing effects. However, the extent to which metaphors in discourse genuinely activate an alternative frame and thereby achieve framing effects has recently been subject to question. Amid calls for more empirical forms of analysis in Critical Discourse Studies, the paper reports two experiments testing the legitimating framing effects of fire metaphors in discourses of disorder. Results show that images of fire and fire metaphors in the absence of competing images facilitate support for police use of water cannon in response to social unrest. The study not only justifies attention to metaphor in CL-CDS but similar effects across semiotic modalities are interpreted as evidence in support of simulation-based theories of metaphor.
\end{abstract}

Key words: metaphor, simulation, framing effects, civil disorder, experimental methods

\section{Introduction}

In Cognitive Linguistic Critical Discourse Studies (CL-CDS), metaphor is identified as a key index of ideology and an important device in the legitimation of social action. From this perspective, metaphor is a cognitive-semiotic operation, invoked by metaphorical expressions in discourse, in which a source frame is mobilised to provide a template for sense-making inside a target frame, leading to particular framing effects. However, the extent to which metaphors in discourse genuinely activate an alternative frame and thereby achieve framing effects has been called into question. In this paper, starting from qualitative analyses of observed discourse data, I report two experiments testing the legitimating framing effects of fire metaphors in discourses of civil disorder. In Section 2, I discuss metaphor as an ideological framing device. In Section 3, I discuss the use of fire metaphors in media discourses of disorder, drawing examples primarily from the 2011 London Riots. In Sections 4 and 5, I present two experimental studies which together shed light on the framing functions of fire metaphors in discourses of disorder.

\section{Metaphor and Framing}

In Cognitive Linguistics metaphor is treated as a matter of thought and action rather than primarily as a matter of language (Lakoff and Johnson 1980; Fauconnier and Turner 2002). From this perspective, metaphor is a cognitive process of frame projection in which a particular source-frame is selected to provide a template for sense-making inside a target frame. Conventional metaphors in 
Pre-proof version. Manuscript accepted for publication in Discourse \& Society.

discourse both reflect and effect underlying metaphorical modes of thought which form a basis for inferencing, decision making and ultimately acting in a given domain.

Frames are conceptual structures representing particular areas of knowledge and experience (Fillmore 1982 1985). They are open-ended, encyclopaedic structures that serve as the cognitive 'base' against which semantically associated words are 'profiled' and understood (Langacker 1987). Frames are modelled in terms of a defining set of frame elements, which are constitutive of a general situation- or event-type, as well as frame-relations in which frames enter into different types of relation with one another (Ruppenhofer et al. 2010). In metaphors, frames for familiar, tangible experiences are selected to provide structure to otherwise complex or underspecified frames. In discourse, frames are accessed or activated by references to the frame or its elements. Frames are Gestalt structures such that any frame-element provides an access point to the rest of the frame which, as a function, is brought to bear in conceptualisation. In metaphor, this means establishing further 'ontological' correspondences between source- and target-frame elements, giving rise to inferential and affective processes rooted in the metaphor (Fauconnier and Turner 2002; Lakoff and Johnson 1980).

From a critical perspective in CL-CDS, metaphor is recognised as an important ideological framing device which achieves framing effects in the legitimation of social actions and relations (CharterisBlack 2004; Chilton 2004; Hart 2010, 2014; Koller 2004, 2014; Musolff 2004, 2006, 2016; Semino 2008). Metaphors define how social situations are to be understood, reasoned about, reacted to emotionally and responded to materially. Metaphor is ideological in so far as metaphorical construals accentuate particular aspects of the target frame while obfuscating others, problematize situations in particular ways and pave the way for decisions and actions which accord with the particular metaphor rather than an alternative mode of presentation. As Semino (2008: 91) puts it, metaphor "has consequences for how a particular issue is 'framed' or structured, which aspects are foregrounded and which are backgrounded, what inferences are facilitated, what evaluative and emotional associations triggered, what courses of action seem to be possible and so on".

The framing power of metaphor in discourse depends on the cognitive activation of the sourceframe. Recently, however, the extent to which the source-frame is genuinely activated by metaphorical expressions has been called into question (Steen 2008, 2010, 2011; Widdowson 2004). According to Steen (2010), for example, it is only a relatively small subset of metaphors, which he calls deliberate metaphors, that cause "the addressee to momentarily adopt another standpoint, in another frame of reference, and to reconsider the local topic from that point of view" (p. 58). Deliberate metaphors are those which are in some way overtly marked as metaphorical. This includes all instances of novel and direct metaphor. Conventional and indirect metaphors, by contrast, may or may not be examples of deliberate metaphor. Similarly, for Widdowson (2004), in many cases the potential for source-frame activation may be defeated by elements in the immediate lexical environment of the putative metaphorical trigger. This is especially the case when those elements or others with similar denotations are in fact conventional collocates of the word purportedly borrowed from another context. ${ }^{1}$

As a form of triangulation in CDS, then, some researchers have suggested the use of corpusinformed 'checks' in critically analysing metaphor (O'Halloran 2007; Widdowson 2004). Such checks

\footnotetext{
${ }^{1}$ Widdowson discusses this in relation to the verb FLOCK used in the context of immigration discourse, which Fairclough (1995: 113) analyses as attributing ovine properties to human migrants. Widdowson shows that in a general corpus of English the predominant arguments of FLOCK are in fact words denoting humans and therefore, based on this evidence, challenges Fairclough's analysis.
} 
Pre-proof version. Manuscript accepted for publication in Discourse \& Society.

work on two assumptions: (i) if a potential metaphorical trigger occurs most frequently in its 'proper' domain, then its use in the current context is likely to activate the source-frame; (ii) if a potential metaphorical trigger occurs most frequently in the current context, then the source-frame is less likely to be activated. However, frequency is not everything and it must be recognised that while usage patterns may provide convergent (or otherwise) evidence of metaphor at the conceptual level, they do not provide empirical evidence of underlying psychological processes. It is therefore difficult to attribute or deny metaphorical frame activation and therefore framing effects on the back of corpus evidence alone.

A further available form of triangulation comes from experimental studies. There is now growing evidence that language understanding involves the activation of mental imagery (Bergen et al. 2007; Kaschak et al. 2005; Stanfield and Zwaan 2001; Zwaan et al. 2002). ${ }^{2}$ Against this simulation view of meaning, it has been shown that understanding metaphor likewise involves the activation of mental imagery (Walsh 1990). This goes equally for highly conventionalised figurative expressions in the form of idioms and proverbs (Gibbs and Bogdonovich 1999; Gibbs and O'Brien 1990; Gibbs et al. 1997). For example, it has been shown that the brain regions involved in perceiving images are similarly involved in processing metaphor (Shibata et al. 2007; Eviatar and Just 2006; Bottini et al. 1994). Priming studies have also demonstrated image-sentence compatibility effects in metaphor comprehension (Ojha and Indurkhya 2016; Paivio and Clark 1986; Valenzuela and Soriano 2007). In the image-first version of this paradigm, metaphor comprehension is facilitated by prior presentation of an image based in the source-frame. In the text-first version, metaphorical language facilitates performance in visual categorisation tasks for source-frame images. The priming effects in both versions of this paradigm point to the important role of mental imagery and perceptual processes in comprehending metaphor. In the image-first version, the effect is due to the mental image evoked by the metaphor already having been formed in response to the image stimulus. In the text-first version, the effect is due to the actual image presented matching the mental image formed in response to the metaphor. Finally, it has also been shown that visually activating a sourceframe can trigger metaphorical language making use of that source-frame - a metaphorical priming effect in language production (Sato et al. 2015).

Psycholinguistic studies add considerable support to theories of metaphor found in Cognitive Linguistics and, by extension, CL-CDS by providing evidence of frame-activation. A further branch of experimental work supports the view of metaphor as an important framing device by empirically demonstrating ideological framing effects (Landau et al. 2009; Lau and Schlesinger 2005; Read et al. 1990; Robins and Mayer 2000; Thibodeau 2016; Thibodeau and Boroditsky 2011, 2013). For example, Landau et al. (2009) showed that participants primed to have a heightened concern about disease contamination - having read a popular science article about harmful airborne bacteria - had harsher attitudes toward immigration when presented with a text in which the country is metaphorically framed as a BODY rather than in literal terms. Thibodeau and Boroditsky (2011) tested the framing effects of two competing metaphors for crime: CRIME IS A DISEASE VS CRIME IS A WILD BEAST. In their experiment, participants read a report about increased crime in a fictitious city in one of the two framing conditions. Participants were then asked what the city needed to do to reduce crime. Responses were coded as either 'reform' or 'enforcement' strategies. It was hypothesised that reform strategies are more consistent with the CRIME IS A DISEASE metaphor (e.g. addressing the root cause) while enforcement strategies are more consistent with the CRIME IS A WILD BEAST metaphor (e.g. instituting harsher penalties). Indeed, Thibodeau and Boroditsky found that participants given the CRIME IS A WILD BEAST framing were more likely to suggest enforcement

\footnotetext{
${ }^{2}$ This is in contrast to strictly symbol-manipulation or amodal accounts of meaning (Fodor 1975; May 1985).
} 
Pre-proof version. Manuscript accepted for publication in Discourse \& Society.

strategies than those given the CRIME IS A DISEASE framing. Interestingly, participants in this experiment were asked to indicate the part of the report that most influenced their response. Overwhelmingly, participants did not point to the metaphorical framing, suggesting that the framing power of metaphor is covert.

Experimental methods are far from the norm in CDS. However, there is increasing call for and use of experimental methods as a form of triangulation within certain CDS frameworks (Fuoli forthcoming; Hart 2016a; Subtirelu and Gopavaram 2016; Widdowson 2004). As Widdowson (2004: 171) states: "whatever textual feature is identified as significant, be it lexical or grammatical, or even typographical, can be systematically altered and the effects of the alteration empirically investigated".

The studies reported above are important for CDS for two reasons. Firstly, they suggest that a focus on metaphor in CL-CDS is fully justified. Secondly, they offer useful templates for experimental design. One issue with many of these studies, though, from a CDS perspective, is that they are not based on prior textual research. In Thibodeau and Boroditsky (2011), for example, no textual evidence for the CRIME IS A DISEASE or CRIME IS A WILD BEAST metaphors is provided. It is therefore not clear that these metaphors constitute conventional framings. Similarly, it is not clear that the CRIME IS A DISEASE metaphor, when used, is actually used to promote reform. In response to the London Riots, for example, then Prime Minister David Cameron made use of this metaphor in describing British society as 'sick' from the gang culture 'infecting' our cities, which we must 'cure'. ${ }^{3}$ Cameron was not using the metaphor to advocate reform, however, but highly anti-progressive measures. Finally, the metaphorical expressions in Thibodeau and Boroditsky's stimuli involved the form $X$ is $Y$ (Crime is a wild beast preying on the city). However, examples of such direct metaphors are actually quite rare in political and media discourses, which tend to favour more indirect metaphorical expressions (e.g. Crime is preying on the city). These issues arise specifically from CDS's commitment to analysing established discourse practices. From a CDS perspective, in any experimental design it is desirable to maintain as much ecological validity as possible and present stimuli in authentic or at least near-authentic form based on attested, conventional usages (Hart 2016a). The starting point in experimental research in CDS should therefore be (patterns in) observed discourse data (ibid.). In discourses of social unrest, one metaphor which is highly conventional is CIVIL DISORDER IS FIRE.

\section{CIVIL DISORDER IS FIRE Metaphor}

Fire metaphors are frequently found in discourses where issues of power, authority and legitimacy are at stake (Charteris-Black 2017). The essential and ubiquitous place that fire holds in human experience seems to make it a perfect candidate in metaphorically grounding complex social phenomena. Moreover, since social organisation depends on abstract notions of transmission, fire provides an ideal model as a concrete and prototypical example of an entity that 'spreads' (Charteris-Black 2017: 27). The FIRE frame, then, is especially rich and vivid. Moreover, in so far as frames are open-ended, encyclopaedic knowledge structures, its activation in discourse is 'cascading'. Any attempt to model the FIRE frame is therefore necessarily partial. However, we can at least identify its most salient structural properties.

3 David Cameron. 10.08.2011 (https://www.gov.uk/government/speeches/pm-statement-on-violence-inengland) and 15.08.2011 ( https://www.gov.uk/government/speeches/pms-speech-on-the-fightback-afterthe-riots). 
In FrameNet (Ruppenhofer et al. 2010), frames are made up of core elements, which are essential to the meaning of a frame, and non-core elements, which do not uniquely characterise the frame but which may nevertheless be a salient feature of it. The FIRE frame is partially modelled in Figure 1. Core elements in the frame include CAUSE, INITIATION, ENDURANCE, EXTENT, SUBSTANCE, TRANSMISSION, SUSTENANCE and CESSATION. These are basic semantic elements which may feature in other frames detailed in frame-specific ways. In the FIRE frame, these elements are accessed and elaborated via lexical indices from the semantic field of fire. Non-core elements include TIME, PLACE, MANNER, MEANS and MATERIALS. Non-core elements are indexed by lexical items which do not necessarily belong to the semantic field of fire but instead provide more circumstantial information. Frames, further, enter into different kinds of frame-to-frame relations. The FIRE frame may be said to entail frames HEAT, LIGHT and NATURAL PHENOMENON. Generic frames may, conversely, be instantiated in frames for specific events salient in cultural memory. Among British citizens, for example, the FIRE frame is likely to be instantiated in a frame for the Great Fire of London. Frame-to-frame relations also include metaphoric relations whereby more concrete, familiar frames act as source frames providing input structure to more abstract areas of experience. Source-frames are typically multivalent whereby they structure a number of different target frames. The FIRE frame metaphorically structures frames including ANGER, DESIRE and CONFLICT (Kövecses 2000). Finally, frames are associated with various, more affective, scripts and scenarios which they evoke when activated in discourse. The FIRE frame is ambiguous in this regard. On the one hand, it is associated with warmth and safety while on the other it is associated with danger and emergency.

\begin{tabular}{lll}
\hline Entails Frames & NATURAL PHENOMENON & \\
HEAT & LIGHT & \\
Elaborated in Frames & GREAT FIRE OF LONDON & \\
Metaphorical Frame Relations & ANGER & \\
& DESIRE & \\
CONFLICT & \\
CAUSE & Spark \\
& INITIATION & Ignite, light, break out, erupt \\
& ENDURANCE & Burn, rage \\
& EXTENT & Engulf, consume \\
& SUBSTANCE & Fire, flames, smoke \\
& TRANSMISSION & Spread \\
& SUSTENANCE & Fuel, fan the flames, inflame \\
Extinguish, put out, burn out
\end{tabular}

Figure 1. Partial model of FIRE frame 
Pre-proof version. Manuscript accepted for publication in Discourse \& Society.

In discourses of social unrest, the FIRE frame is appropriated in the metaphor CIVIL DISORDER IS FIRE. This metaphorical framing is found, for example, in the following instances taken from media discourse in response to the 2011 London Riots, both in the immediate wake of the riots (1-4) and as part of later reflections on them (5-7):

(1) A riot that engulfed north London was sparked when a teenage girl threw a rock at police, it was claimed last night (Daily Star 08.08.11)

(2) Riots have raged over the last few days in London (Daily Mail 10.08.11)

(3) Rioting has spread across London on a third night of violence, with unrest flaring in other English cities (BBC News 09.08.11)

(4) Riots which took hold of London for three nights have spread to other parts of England ( $B B C$ News 10.08.11)

(5) Published today, an interim report by the Riots Communities and Victims Panel found that the 'blanket coverage' on television, online and via mobile platforms helped fan the flames of unrest (Digital Spy 28.03.12)

(6) Duggan's death ... was the spark that ignited the worst riots in England for decades, starting in London and quickly spreading to other cities (Telegraph 31.01.13)

(7) Riots, sparked by the police killing of Mark Duggan, engulfed cities in the UK for five nights in 2011 (Guardian 02.08.16)

This metaphor is not limited in its context of use to the London Riots, however. Rather, it is part of a conventional repertoire for reporting social unrest. The metaphor is also found, for example, in media discourses of the 2015 Baltimore Riots in the U.S. and the 'Arab Spring' that began in Egypt in 2010 (Charteris-Black 2017; Hart 2014; Hawkins 2014). Neither is the metaphor restricted to reporting contemporary events but is found instead to have a 'discourse history' (Musolff 2007) which cuts across different genres or 'fields of action' (Reisigl and Wodak 2001). Example (8) comes from parliamentary discourse on the 1981 Riots that took place in Toxteth, Liverpool:

(8) Unemployment, housing, racial tension and policing have all played their part, but the House must also look at those who fan the flames. The chief constable of Manchester spoke of a conspiracy. It is certainly true that on the nights when riots flared in Liverpool every lunatic from the extreme wings of politics seemed to be on the streets of Liverpool. Someone was organising the petrol bombs. There were people in hoods overturning cars, causing disruption and deliberately helping those who wanted to fan the flames of the violence. People were also distributing leaflets. Other hon. Members have already referred to leaflets that were distributed in their own constituencies. The House will recall that immediately after the riots I brought to the attention of the Home Secretary a leaflet that was deliberately designed to incite and inflame the situation in central Liverpool. (David Alton, MP Liverpool Edge Hill, 16 July 1981)

Examples (1) - (8) show that different elements of the FIRE frame can be indexed to (potentially) invoke a metaphoric construal of civil disorder. In standard cognitive metaphor theory, it is precisely this kind of systematic reference to the various aspects of the FIRE frame that counts as evidence of an underlying conceptual metaphor CIVIL DISORDER IS FIRE. Corpus analysis can further support the hypothesis that the lexical items highlighted are likely to invoke the FIRE frame in a metaphorical construal. For example, the top three noun collocates of engulf in the British National Corpus are 
flames $(n=27, \operatorname{LLV}=288.0402)$, fire $(n=11, L L V=61.1046)$ and smoke $(n=5, L L V=32.4596)$. CharterisBlack (2007: 21) similarly shows that major collocates of spread belong to the semantic field of fire. ${ }^{4}$ Neither of these forms of evidence, however, empirically demonstrates frame-activation or framing effects.

Motivation for the CIVIL DISORDER IS FIRE metaphor may be embodied, representing a particular elaboration of the metaphor ANGER IS HEAT, which is rooted in our phenomenological experience of these two domains as co-related (Grady 1999; Kövecses 2000). ${ }^{5}$ Alternatively, the metaphor may be 'situationally triggered' (Semino 2009), motivated by the real instances of fire that sometimes occur as part of riots and protests and congruent with images of fire co-textually present in multimodal news texts. ${ }^{6}$ Regardless of motivation, a number of potential framing effects arise from activation of the FIRE frame in this context.

For example, at the most general level, fire metaphors may invite a negative evaluation of protests and protesters, given our primary understanding of fire as a destructive force (Charteris-Black 2017: 22). More specifically, the FIRE frame serves to reduce, via a process of compression (Fauconnier and Turner 2002), the CAUSE(S) of the event to another single event in time - a 'spark'. In the case of the London Riots, the 'spark' that 'ignited' the riots was the death of Mark Duggan. The metaphorical framing therefore occludes attention to the complex and enduring structural conditions that ultimately lead to the event. Similarly, INITIATION of the event may be reduced to a spontaneous 'eruption' without cause or agency. Agency is also removed from the process of TRANSMISSION as fire 'spreads' naturally and inevitably. As Hawkins (2014: 37) states: "a difficulty with such as metaphor is that it leaves little room for analysing the paths and means of transmission. The spread of a fire appears inevitable and disconnected from human actions". The metaphor therefore serves to naturalise instances of civil disorder, detaching them from human motives, and thus depoliticising them. Emotional effects may also arise as the FIRE frame, in this context, promotes danger and emergency scenarios. And, as part of these scenarios, the metaphor may prime particular courses of action as appropriate within the 'logic' of the metaphor. For example, the prototypical means of controlling fire is with water. In the metaphorical framing, it may therefore become acceptable to control protests in the same way. When projected back to the target frame, this legitimated action translates as using water cannon. Crucially, however, the target-frame action has been legitimated on the back of a metaphorical understanding of the situation.

These critical analyses amount to testable hypotheses concerning cognitive responses of readers. However, the extent to which this metaphor actually succeeds in achieving any framing effects remains unverified. In the following section, therefore, by way of triangulation, I report a recent

\footnotetext{
${ }^{4}$ Other major collocates of spread belong to the semantic fields of disease (the infection spread) and language/communication (spreading rumours). Words like spread or break out may thus be described as semantically 'loose', less tightly bound to a single frame. In discourses of disorder, though, they are likely to activate the FIRE frame rather than any alternative as a function of the wider discursive context (i.e. surrounding discourse practices) which makes this reading more readily available and therefore, in processing terms, the most 'relevant' (Sperber and Wilson 1995).

${ }^{5}$ In Cognitive Linguistics, 'motivation' does not refer to why particular semiotic choices are made, but to why those choices are available in the first place (Radden and Panther 2004).

${ }^{6}$ Images of fire at riots and protests satisfy a news value of conflict/dramatization (Craig 1994). Therefore, when a protest does involve fire, this will typically be focussed on in visual representations as part of the 'protest paradigm' identified by Chan and Lee (1984).
} 
Pre-proof version. Manuscript accepted for publication in Discourse \& Society.

experiment testing the effects of fire metaphors in media discourses of disorder on the perceived legitimacy of police use of water cannon. ${ }^{7}$

\section{Experiment 1}

\subsection{Research Question and Hypotheses}

The experiment aimed to show whether fire metaphors in discourses of disorder affect perceptions of water cannon as a legitimate form of police response to social unrest. A number of studies have shown that the images, in the form of press photographs, presented in multimodal news texts achieve framing effects (e.g. Arpan et al. 2006; Gibson and Zillmann 2000; Zillmann, Gibson and Sargent 1999). For example, Arpan et al. (2006) showed that, in images of social protests, when the issue was of interest to readers, photographs depicting higher levels of conflict lead to more negative evaluations of the protest and protesters. The literature on metaphor cited in the previous sections suggests that metaphor involves the activation of mental imagery associated with the source-frame and that this frame-activation will lead to framing effects in contexts of political communication. If metaphor does indeed activate mental imagery associated with the sourceframe, then we should expect to see similar framing effects between images in news texts and congruent mental imagery invoked by metaphor in news texts. This leads to the following primary research question and hypotheses:

RQ: Do fire metaphors in media discourses of disorder contribute to a perceived legitimacy of using water cannon in police response to civil unrest?

H1: The presence of fire in images of protest will facilitate support for police use of water cannon

H2: The presence of fire in metaphors of protests will similarly facilitate support for police use of water canon

\subsection{Participants}

A total of 237 participants were recruited via Amazon's Mechanical Turk (www.mturk.com) (Buhrmester, Kwang and Gosling 2011; Crump, McDonnel and Gureckis 2013; Mason and Suri 2012; Paolacci, Chandler and Ipeirotis 2010). Participation was restricted to users registered in the UK, the U.S., the Republic of Ireland, Canada and Australia. To ensure high quality participants only "Turkers" with a HIT Approval Rate of $98 \%$ or above were eligible. This rating indicates that participants had completed at least $98 \%$ of previous tasks satisfactorily. Other measures were also taken to ensure high quality responses (see Procedure).

7 participants were excluded as non-native speakers of English. Native speakers were defined as those speaking or learning English since birth and currently using English as their primary language (by self-report). A further 3 participants were excluded for failing an attention check. The final

\footnotetext{
${ }^{7}$ Police use of water cannon is a controversial issue. In the UK, it is currently illegal except in Northern Ireland. However, in the wake of the London Riots, David Cameron stated that water cannon would be made available to the police at 24 hours' notice for future disturbances. In 2014, Metropolitan Police Commissioner Sir Bernard-Hogan Howe publicly argued the case for police use of water cannon. Also in 2014, London Mayor Boris Johnson went ahead and authorised the purchase of three water cannon at a cost of $£ 328,883$.
} 
Pre-proof version. Manuscript accepted for publication in Discourse \& Society.

sample included 227 participants. Participant characteristics are detailed in Table 1 . The majority of participants fell in the age range 25-44 years while gender was evenly balanced between male and female. More participants reported a conservative than a liberal or independent political orientation.

\begin{tabular}{cccccccccc}
\hline & \multicolumn{2}{c}{ Age-Range } & \multicolumn{3}{c}{ Gender } & \multicolumn{3}{c}{ Political Orientation } \\
\hline $16-24$ & $25-44$ & $45-64$ & $65+$ & Male & Female & Other & Lib & Con & Ind \\
23 & 149 & 52 & 3 & 114 & 112 & 1 & 62 & 112 & 53 \\
\hline
\end{tabular}

Table 1. Participant Characteristics Experiment 1

\subsection{Methods}

\section{Materials and Design}

To test the hypotheses, participants took part in an online survey-embedded experiment. Participants were presented with an online news text reporting a recent political protest in the fictitious city of Sudfield. The stimulus text was mocked up to feel like a genuine online news text and took the same basic compositional form, with relative size and positions etc. preserved, in each condition (see Figure 2). Participants were randomly assigned to one of three conditions: (1) fire not present in the images or in the written text $(n=74)$; (2) fire present in the images but not in the written text $(n=78)$; (3) fire present in the written text but not in the images $(n=75) .^{8}$

Images were selected from real pictures of protests published in the online content of major UK newspapers. They were matched as closely as possible across conditions for visuo-grammatical and social actor classification features (Machin and Mayr 2012). For example, in conditions 1 and 3, Image $B$ showed an individual college-age male throwing a flare in front of a burning car. In condition 2, Image B showed an individual college-age male vandalising a parked police van. It should be noted, however, that fully controlling for the myriad potential visuo-semiotic variables is not possible, especially when relying on real images. The presence of fire in condition 2 images also necessarily meant there were significant differences in colour (hue, brightness, saturation) between conditions. Fire was a salient feature in all condition 2 images.

The written text consisted of a headline, shown in capitals, followed by a lead paragraph. This text was constructed from attested discourse practices and is therefore near-authentic. The literal and metaphorical versions of the text differed only according to the presence of FIRE frame indices. Texts were otherwise matched for length and syntactic complexity as well as for typographical features. The metaphorical text contained 4 indirect instances of the CIVIL DISORDER IS FIRE metaphor, no direct

\footnotetext{
${ }^{8}$ Where riots and protests do sometimes involve fire, linguistic references to the FIRE frame may, of course, be literal. In this paper, however, I am interested in metaphorical framing effects. Therefore, in the stimuli, all references to fire were figurative.
} 
Pre-proof version. Manuscript accepted for publication in Discourse \& Society.

metaphors and no instances of competing metaphors based in alternative source-frames. The literal and metaphorical texts are reproduced below. ${ }^{9}$

Literal text (conditions 1 and 2):

\section{PROTESTS OVERWHLEM CITY}

Protests have overwhelmed the city of Sudfield. The protests started in the morning but quickly extended throughout the city where they continued to occur all day. Eventually the police used water cannon to disperse the protesters.

Metaphorical text (condition 3):

\section{PROTESTS ENGULF CITY}

Protests have engulfed the city of Sudfield. The protests ignited in the morning but quickly spread throughout the city where they continued to rage all day. Eventually the police used water cannon to disperse the protesters.

Some studies have demonstrated the framing power of metaphor by comparing framing effects of two different metaphorical framings (e.g. Thibodeau and Boroditsky 2011). However, others have argued that comparing metaphorical to non-metaphorical framings is more useful in demonstrating the influence of metaphor (Reijnierse et al. 2015; Steen, Reijnierse and Burgers 2014). While metaphorical framings can and almost always do differ from literal framings along a number of linguistic dimensions (e.g. imagery, valence, arousal) as an inherent function of metaphor, searching for alternative metaphorical conditions can result in forced metaphors which do not reflect the way people use metaphor to think about the target frame in normal circumstances. This is problematic for several reasons. From a CDS perspective, non-attested framings are not of particular interest. Moreover, forced metaphors will stand out compared to conventional metaphors, both reducing the ecological validity of the experiment and rendering the two conditions unequal in other respects. As in any experimental study of framing effects, then, a balance must be struck between internal and external, ecological validity. In this study, the fire not present at all condition serves as a baseline for comparison in both the image and metaphor manipulations. We are therefore comparing metaphorical framings (condition 3 ) to literal counterparts (condition 1).

\footnotetext{
9 'Protest' rather than 'riot' is used in the stimuli texts as the more neutral term (Fang 1994)
} 


\section{THE DAILY NEWS}

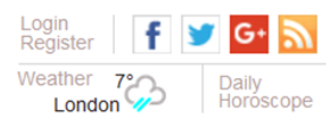

London

\section{HOME NEWS SHOWBIZ \& TV SPORT COMMENT FINANCE TRAVEL ENTERTAINMENT LIFE \& STYLE}

UK WORLD POLITICS ROYAL HISTORY NATURE SCIENCE WEIRD OBITUARIES SUNDAY SCOTLAND WEATHER

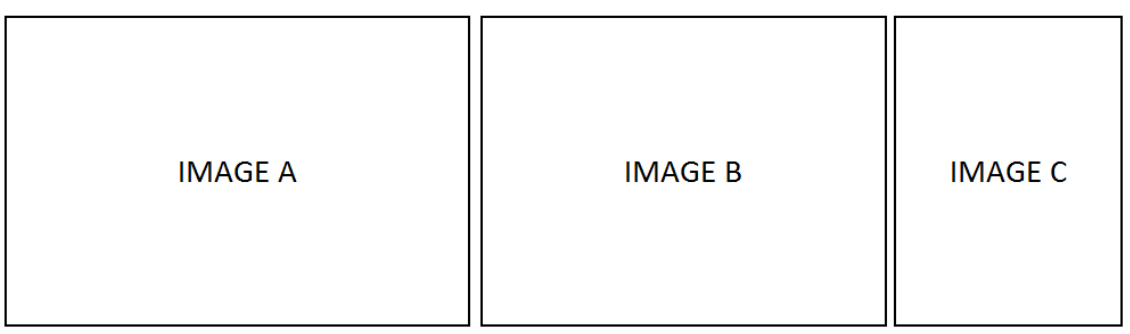

\section{HEADLINE}

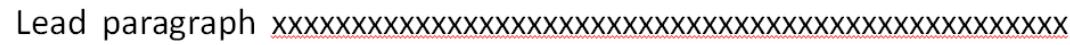

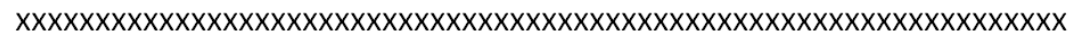

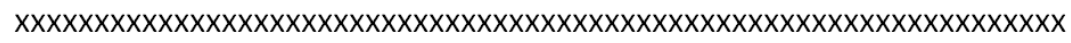
$x x x x x x x x x x x x x x x x x x x x x$

By continuing to use the site, you agree to the use of cookies. You can find out more by following this link.

Figure 2. Stimulus Text Template

\section{Procedure}

Upon entering the experiment, participants were told that they would see a newspaper front page before being asked two follow-up questions about the text. They were instructed to read the text carefully before progressing through the experiment. They were also told not to use the "back" button on their web-browser as this would terminate the session. This was to ensure that participants did not re-read the stimulus text in light of the follow-up questions or in order to pass the attention check.

Once participants confirmed that they had read the instructions and were ready to proceed, they were randomised to one of the three stimulus conditions. Stimulus texts were displayed for a minimum of 15 seconds before participants were able to move on. This was to encourage participants to fully engage with the text. To ensure that participants had read the text, they next had to complete an attention check in which they were asked to list three words they remembered from the news story. The dependent measures were then displayed. At the end of the survey, participants were asked to provide basic demographic information, including age range, gender and political orientation.

\section{Measures}

After reading the stimulus text, participants answered two questions which measure the dependent variable. Discursive legitimation is defined as the act of attributing acceptability to controversial actions within the normative order (Martin Rojo and van Dijk 1997: 560-561). Previous studies 
Pre-proof version. Manuscript accepted for publication in Discourse \& Society.

addressing the discursive legitimation of social action suggest that legitimation is a function of logical rationalisation and moral justification (Chilton 2004; Martin Rojo and van Dijk 1997; Reyes 2011; van Leeuwen 2007; van Leeuwen and Wodak 1999). Participants were therefore asked the following two questions (counter-balanced for order):

1. How logical was the decision to use water canon at the protests in Sudfield?

2. How justifiable was the decision to use water canon at the protests in Sudfield?

Both questions were answered on a 7-point semantic differential scale $(1=$ not very logical/justifiable, $7=$ very logical/justifiable). Responses were then averaged to create a perceived legitimacy rating (PLR) for each participant. To analyse the data, PLRs were divided into three categories: Low (1-3.9), Middle (4-4.9) and High (5-7). A chi square test was used to analyse the effect of framing condition on the dependent variable.

\subsection{Results and Discussion}

Compared to the base condition, the presence of fire in images produced a framing effect in legitimating police use of water cannon. As shown in Figure 3, participants presented with images containing fire were more likely to consider police use of water cannon as legitimate (65\% high PLR) compared to participants in the base condition (43\% high PLR) $\left(\chi^{2}=16.97, p<.001\right)$. These results thus confirm Hypothesis 1 . Contrary to Hypothesis 2, however, the presence of fire metaphors in the written text did not lead to any significant framing effects compared to the base condition $\left(\chi^{2}=\right.$ $1.28, n s)$. At first blush, this may be taken as evidence that such highly conventional metaphors do not involve source-frame activation and therefore do not achieve framing effects. However, an alternative interpretation is that the FIRE frame is not activated in this context because it is defeated by the presence of competing images in co-text (i.e. images that do not contain fire). This interpretation falls in line with previous studies which show that when there is incongruence between the two modalities it is images that override divergent textual information (Gibson and Zillmann 2000; Powell et al. 2015). On this account, then, it is suggested that the formation of mental imagery in response to metaphor is prevented by incongruent imagery already held in mind as a result of visuals in the text. In other words, we find a form of interference effect based on an image-first reading of the text. This interpretation is supported by evidence from eye-tracking studies which show that images are the most typical entry points to news texts (Holsanova, Holmqvist and Rahm 2006; Garcia and Stark 1991; Wartenberg and Holmqvist 2005). Of course, this interpretation suggests that in the absence of competing images, source-frame imagery will be freely formed and we will therefore find similar framing effects for metaphors as for actual images based in the same frame. Thus, in a follow-up experiment, the same metaphor manipulation was presented but in a mono-modal text. 
(a)

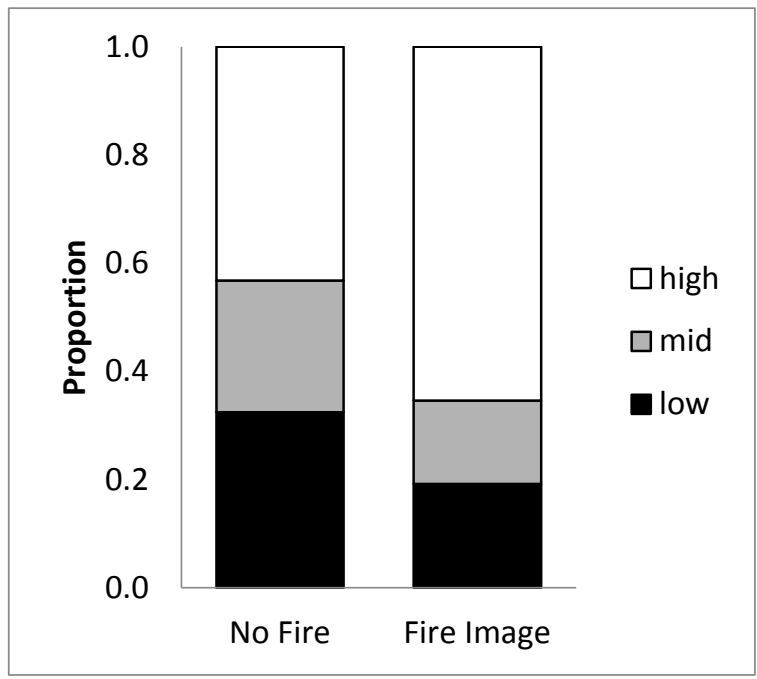

(b)

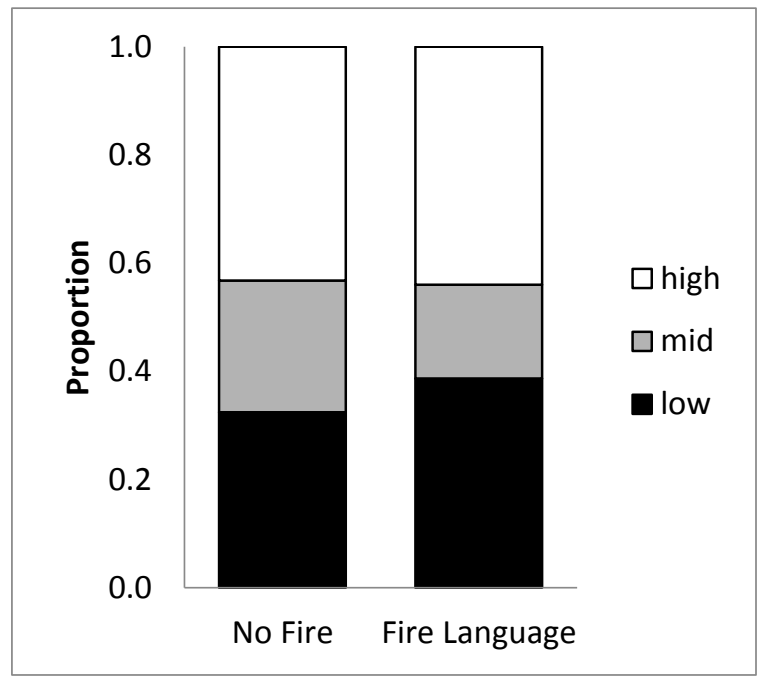

Figure 3. Legitimating effects of fire in (a) images and (b) mental imagery invoked by metaphor. Proportion of sample is plotted on the $\mathrm{Y}$-axis.

\section{Experiment 2}

\subsection{Research Question and Hypothesis}

Following from Experiment 1, Experiment 2 aimed to show that, in the absence of co-textually present competing images, fire metaphors in discourses of disorder will facilitate support for police use of water cannon in response to civil unrest.

\subsection{Participants}

A total of 145 participants were recruited via Amazon's Mechanical Turk. The same eligibility criteria were applied as in Experiment 1 with the addition that Turkers who had completed Experiment 1 were precluded from participation in Experiment 2. 2 participants were excluded as non-native speakers and a further 3 participants were excluded for failing the attention check. The final sample included 140 participants. Participant characteristics are detailed in Table 2. The majority of participants fell in the 25-44 age range while gender was evenly balanced between male and female. More participants reported a liberal than a conservative or independent political orientation.

\begin{tabular}{ccccccccccc}
\hline & \multicolumn{2}{c}{ Age-Range } & & \multicolumn{3}{c}{ Gender } & \multicolumn{3}{c}{ Political Orientation } \\
\hline $16-24$ & $25-44$ & $45-64$ & $65+$ & Male & Female & Other & Lib & Con & Ind \\
25 & 86 & 27 & 2 & 69 & 70 & 1 & 67 & 33 & 40 \\
\hline
\end{tabular}

Table 2. Participant Characteristics Experiment 2 
Pre-proof version. Manuscript accepted for publication in Discourse \& Society.

\subsection{Methods}

Experiment 2 employed the same methods as Experiment 1 except that stimulus texts were presented without images (the rest of the template remained the same) and participants were assigned to one of only two conditions: literal $(n=71)$ and metaphorical $(n=69)$. The written texts used in the literal and metaphorical conditions were the same as in Experiment 1.

\subsection{Results and Discussion}

Compared to the literal, base condition, the metaphorical condition lead to framing effects in legitimating police use of water cannon. As shown in Figure 4, participants presented with fire metaphors were more likely to consider police use of water cannon as legitimate ( $54 \%$ high PLR) compared to participants presented with the literal text (41\% high PLR) $\left(\chi^{2}=7.1926, p<.05\right)$. The results thus confirm the original Hypothesis 2 with the added qualification in the absence of competing images.

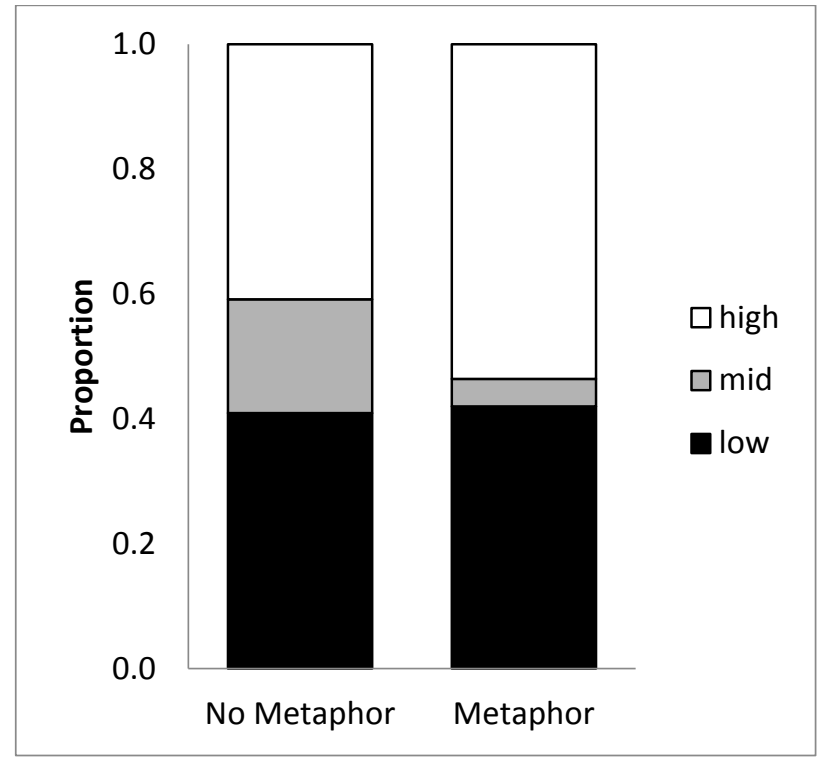

Figure 4. Legitimating effects of fire metaphors. Proportion of sample is plotted on the $\mathrm{Y}$-axis.

Of course, people do not process texts free from a priori political values (Widdowson 2004). Indeed, political orientation is another significant predictor of PLRs for police use of water cannon. ${ }^{10} 61 \%$ of participants who reported a conservative orientation and $60 \%$ of participants who reported an independent orientation perceived police use of water cannon as legitimate while only $33 \%$ of participants who reported a liberal orientation saw water cannon as a legitimate form of police response. It is worth noting here that political orientations divided evenly across test conditions ( metaphor condition $=49 \%$ of liberals, $58 \%$ of conservatives and $43 \%$ of independents) and all

\footnotetext{
${ }^{10}$ Age and gender were not significant factors.
} 
Pre-proof version. Manuscript accepted for publication in Discourse \& Society.

political orientations showed an increase in perceived legitimacy in the metaphorical condition, suggesting that metaphor and political orientation are independent influences. This is confirmed statistically where there is no significant relationship between the two factors $\chi^{2}=1.6443, p=$ $.439493, n s)$.

Metaphor was not a significant factor for any single political orientation but only within the sample population as a whole. However, some political orientations were more sensitive than others. Among participants who reported conservative and independent political orientations, PLRs in the "high" category increased by $6 \%$ and $8 \%$ respectively in the metaphorical condition while for participants who identified as liberal, high PLRs increased by $18 \%$. Thus, in line with previous studies (Thibodeau and Boriditsky 2011; Hart 2016a), conservatives are found to be least susceptible to textual influence and liberals most susceptible. Interestingly, in these results, independents pattern closer to conservatives than they do to liberals. This suggests that conservatives and independents are more fixed in their attitudes and opinions toward political protests and policing, subscribing to a discourse of deviance, while liberals formulate their views on a more context-dependent basis taking into account local information supplied by texts.

\section{General Discussion and Conclusion}

This study employed experimental methods to investigate the legitimating framing effects of the metaphor CIVIL DISORDER IS FIRE found in media discourses of social unrest. The results showed that images of fire in multimodal news texts and fire metaphors in the absence of competing images both achieve framing effects in legitimating police use of water cannon. This case study suggests that media representations in both language and image can influence public opinion on matters of policing.

The similar effects observed across modalities suggest that understanding metaphorical language involves activation of mental imagery associated with source-frames which, in turn, leads to framing effects. It could be argued that the results do not necessarily demonstrate the role of imagery in processing metaphor and that the framing effect observed in Experiment 2 is simply due to lexical association. In Experiment 1, however, the same metaphorical framing was shown not to achieve framing effects when accompanied by incongruent images in co-text. This is interpreted as a form of interference effect, whereby the presence of incompatible images inhibits the formation of mental imagery in response to metaphor as we cannot simultaneously hold conflicting images in mind. In light of experiment 2, then, the null result in experiment 1 is actually taken as evidence of the role of imagery in metaphor processing. As well as justifying attention to metaphor in CDS, the study therefore also adds weight to embodied simulation theories of metaphor such as found in Cognitive Linguistics. The study, moreover, contributes to text-image relations theory (Bateman 2014) by highlighting a further dimension along which language and image may converge or diverge. It would be interesting to investigate whether, in a corpus of news data, metaphors and images tend to be congruent with one another or if there is typically cross-modal conflict between them.

Legitimating effects were stronger for images than mental imagery invoked by metaphor. This is to be expected since images are objectively presented to readers and are directly perceived. They are therefore more concrete and less variable. By contrast, mental imagery invoked by metaphor is removed from direct visual experience, is therefore less opulent and is more subjective. This is also in line with previous studies which show that images achieve stronger framing effects than language (Gibson and Zillmann 2000; Powell et al. 2015). This has clear implications for CDS. It suggests that 
Pre-proof version. Manuscript accepted for publication in Discourse \& Society.

linguistic meaning is, in part at least, a function of multimodal context and, therefore, that specific language usages cannot be critically interpreted without reference to the specific multimodal contexts in which they are embedded. This extends beyond immediate co-text to the intertextually linked images that make up the relevant background visuo-semiotic experience for any utterance (Hart 2016b). It also suggests that in multimodal texts it is images that play a primary role in discursively constructing situations and events with language serving a further contextualising, disambiguating or framing function but not a re-framing function (Geise and Baden 2014). The experiments did not test the impact of convergence between language and image but it can be assumed that congruity between modes would lead to even stronger framing effects (Graber 1990; Paivio 1991).

Finally, the study has more general implications for CDS. This mixed-methods study has shown the utility of employing experimental techniques as a form of triangulation in CDS. Experimental methods enable hypotheses emerging from qualitative critical discourse analyses to be empirically verified and help shed further light on the mechanisms by which textual influence occurs.

\section{References}

Arpan, L.M., K. Baker, L. Youngwon, J. Taejin, L. Lorusso and J. Smith (2006). News coverage of social protests and the effects of photographs on prior attitudes. Mass Communication \& Society 9 (1): $1-20$.

Bateman, J. (2014). Text and Image: A Critical Introduction to the Visual/Verbal divide. London: Routledge.

Bergen, B., S. Lindsay, T. Matlock and S. Narayanan (2007). Spatial and linguistic aspects of visual imagery in sentence comprehension. Cognitive Science 31: 733-764.

Bottini, G., R. Corcoran, R. Sterzi, E.S.P. Paulesu, P. Scarpa, R.S.J. Frackoviak et al. (1994). The role of the right hemisphere in the interpretation of the figurate aspects of language: A positron emission tomography activation study. Brain 117: 1241-1253.

Buhrmester M.D., T. Kwang and S.D. Gosling (2011). Amazon's Mechanical Turk: A new source of inexpensive, yet high-quality, data? Perspectives on Psychological Science 6 (1): 3-5.

Chan, J.M. and C.C. Lee (1984). The journalistic paradigm on civil protests: A case study of Hong Kong. In A. Arno and W. Dissanayake (eds.), The News Media in National and International Conflict. Boulder, CO: Westview. pp. 183-202.

Charteris-Black, J. (2004). Corpus Approaches to Critical Metaphor Analysis. Basingstoke: Palgrave Macmillan

Charteris-Black, J. (2017). Fire Metaphors: Discourses of Awe and Authority. London: Bloomsbury.

Chilton, P. (2004). Analysing Political Discourse: Theory and Practice. London: Routledge.

Craig, G. (1994). Press photographs and news values. Australian Studies in Journalism 3: 182-200.

Crump, J.C., J.V. McDonnel and T.M. Gureckis (2013). Evaluating Amazon's Mechanicial Turk as a tool for experimental behavioural research. PLOS ONE 8 e57410. 
Pre-proof version. Manuscript accepted for publication in Discourse \& Society.

Eviatar, Z. and M.A. Just (2006). Brain correlates of discourse processing: An fMRI investigation of irony and conventional metaphor comprehension. Neuropsychologia 44 (12): 2348-2359.

Fairlcough, N. (1995). Media Discourse. London: Edward Arnold.

Fang, Y-W. (1994). 'Riots' and demonstrations in the Chinese press: A case study of language and ideology. Discourse \& Society 5 (4): 463-482.

Fauconnier, G. and M. Turner (2002). The Way We Think: Conceptual Blending and the Mind's Hidden Complexities. New York: Basic Books.

Fillmore, C. (1982). Frame semantics. In Linguistics Society of Korea (eds.), Linguistics in the Morning Calm. Seoul: Hanshin Publishing Co. pp. 111-37.

Fillmore, C. (1985). Frames and the semantics of understanding. Quaderni di Semantica VI (2):222254.

Fodor, J. (1975). The Language of Thought. New York: Crowell.

Fuoli, M. (forthcoming). Using experimental methods to assess the persuasiveness of corporations' trust-repair discourse strategies.

Garcia, M.R. and P.A. Stark (1991). Eyes on the News. St Petersburg, FL: The Poynter Institute.

Giese, S. and C. Baden (2014). Putting the image back into the frame: Modeling the linkage between visual communication and frame-processing theory. Communication Theory 25 (1): 46-69.

Gibbs, R. and J. Bogdonovich (1999). Mental imagery in interpreting poetic metaphor. Metaphor and Symbol 14: 37-44.

Gibbs, R. and J. O'Brian (1990). Idioms and mental imagery: The metaphorical motivation for idiomatic meaning. Cognition 36: 35-68.

Gibbs, R., L. Strom and M. Spivey-Knowlton (1997). Conceptual metaphor in mental imagery for proverbs. Journal of Mental Imagery 21: 83-110.

Gibson, R. and D. Zillmann (2000). Reading between the photographs: The influence of incidental pictorial information on issue perception. Journalism \& Mass Communication Quarterly 77 (2): 355-366.

Grady, J. (1999). A typology of motivation for conceptual metaphor: Correlation vs. resemblance. In G. Steen and R. Gibbs (eds.), Metaphor in Cognitive Linguistics. Amsterdam: John Benjamins. pp. 79-100.

Graber, D. (1990). Seeing is remembering: How visual contribute to learning from television news. Journal of Communication 40 (3): 134-155.

Hart, C. (2010). Critical Discourse Analysis and Cognitive Science: New Perspectives on Immigration Discourse. Basingstoke: Palgrave.

Hart, C. (2014). Discourse, Grammar and Ideology: Functional and Cognitive Perspectives. London: Bloomsbury.

Hart, C. (2016a). Event-frames affect blame assignment and perception of aggression in discourse on political protests: An experimental case study in critical discourse analysis. Applied Linguistics. 
Pre-proof version. Manuscript accepted for publication in Discourse \& Society.

Hart, C. (2016b). The visual basis of linguistic meaning and its implications for CDS: Integrating cognitive linguistic and multimodal methods. Discourse \& Society 27 (3): 335-350.

Hawkins, S. (2014). Teargas, flags and Harlem shake: Images of and for revolution in Tunisia and the dialectics of the local in the global. In P. Werbner, M. Webb and K. Spellman-Poots (eds.), Global Protest: The Arab Spring and Beyond. Edinburgh: EUP. pp. 31-52.

Holsanova, J., K. Holmqvist and H. Rahm (2006). Entry points and reading paths on newspaper spreads: Comparing a semiotic analysis with eye-tracking measurements. Visual Communication 5 (1): 65-93.

Kaschak M, Madden CJ, Therriault DJ, Yaxley RH, Aveyard M, Blanchard AA and Zwaan RA (2005) Perception of motion affects language processing. Cognition 94 (3): B79-B89.

Koller, V. (2004). Metaphor and Gender in Business Media Discourse: A Critical Cognitive Study. Basingstoke: Palgrave.

Koller, V. (2014). Cognitive linguistics and ideology. In J. Littlemore and J. Taylor (eds.), The Bloomsbury Companion to Cognitive Linguistics. London: Bloomsbury. pp. 234-252.

Kövecses, Z. (2000). Metaphor and Emotion: Language, Culture and Body in Human Feeling. Cambridge: Cambridge University Press.

Lakoff, G. and M. Johnson (1989). Metaphors We Live by. Chicago: University of Chicago Press.

Landau, M.J., D. Sullivan and J. Greenberg (2009). Evidence that self-relevant motives and metaphoric framing interact to influence political and social attitudes. Psychological Science 20 (11): 1421-1426.

Langacker, R.W. (1987). Foundations of Cognitive Grammar, Volume I: Theoretical Prerequisites. Stanford, CA: Stanford University Press.

Lau, R.R. and M. Schlesinger (2005). Policy frames, metaphorical reasoning, and support for public policies. Political Psychology 26 (1): 77-113.

Machin D and Mayr A (2012) Critical Discourse Analysis: A Multimodal Approach. London: Sage.

Mason, W. and S. Suri (2012). Conducting behavioural research on Amazon's Mechanical Turk. Behavioural Research Methods 44: 1-23.

May, R. (1985). Logical Form. Cambridge: MIT Press.

Martin Rojo, L. and T.A. Van Dijk (1997). “There was a problem, and it was solved!” Legitimating the expulsion of 'illegal' immigrants in Spanish parliamentary discourse. Discourse \& Society 8 (4): 523-567.

Musolff, A. (2004). Metaphor and Political Discourse: Analogical Reasoning in Debates about Europe. Basingstoke: Palgrave.

Musolff, A. (2006). Metaphor scenarios in public discourse. Metaphor and Symbol 21 (1): 23-38.

Musolff, A. (2007). Is there such a thing as a discourse history: The case of metaphor. In C. Hart and D. Lukeš (eds.), Cognitive Linguistics in Critical Discourse Analysis: Application and Theory Newcastle: Cambridge Scholars Publishing. pp.1-27.

Musolff, A. (2016). Political Metaphor Analysis: Discourse and Scenarios. London: Bloomsbury. 
Pre-proof version. Manuscript accepted for publication in Discourse \& Society.

O'Halloran, K. (2007). Critical discourse analysis and the corpus-informed interpretation of metaphor at the register level. Applied Linguistics 28 (1): 1-24.

Ojha, A. and B. Indurkhya (2016). On the role of perceptual features in metaphor comprehension. In E. Gola and F. Ervas (eds.), Metaphor and Communication. Amsterdam: John Benjamins. pp.147-170.

Paolacci, G., J. Chandler and P.G. Ipeirotis (2010). Running experiments on Amazon Mechanical Turk. Judgement and Decision Making 5: 411-419.

Paivio, A. (1991). Images in Mind. New York: Harvester Wheatsheaf.

Paivio, A. and J.A. Clark (1986). The role of topic and vehicle imagery in metaphor comprehension. Communication and Cognition 19 (3-4): 367-387.

Powell, T.E., H.G. Boomgaarden, K. DeSwert and C.H. de Vreese (2015). A clearer picture: The contribution of visuals and text to framing effects. Journal of Communication 65 (6): 997-1017.

Radden, G. and K-U. Panther (eds.) (2004). Studies in Linguistic Motivation. Berlin: Mouton de Gruyter.

Read, S., I. Cesa, D. Jones and N. Collins (1990). When is the federal budget like a baby? Metaphor in political rhetoric. Metaphor and Symbol 5 (3): 125-149.

Reijnierse, W.G., C. Burgers, T. Krennmayr and G.J. Steen (2015). How viruses and beasts affect our opinions (or not): The role of extendedness in metaphorical framing. Metaphor and the Social World 5 (2): 245-263.

Reisigl, M. and R. Wodak (2001). Discourse and Discrimination: Rhetorics of Racism and AntiSemitism. London: Routledge.

Reyes, A. (2011). Strategies of legitimization in political discourse: From words to actions. Discourse \& Society 22 (6): 781-807.

Robins, S. and R.E. Mayer (2000). The metaphor framing effect: Metaphorical reasoning about textbased dilemmas. Discourse Processes 30 (1): 57-86.

Ruppenhofer, J., M. Ellsworth, M.R.L. Petruck, C.R. Johnson and J. Scheffczyk (2010). FrameNet II: Extended Theory and Practice. Available at: https://framenet2.icsi.berkeley.edu/docs/r1.5/book.pdf

Sato, M., A.J. Schafer and B.K. Bergen (2015). Metaphor priming in sentence production: Concrete pictures affect abstract language production. Acta Psychologica 156: 136-142.

Shibata, M., J. Abe, A. Terao and T. Miyamoto (2007). Neural mechanisms involved in the comprehension of metaphoric sentences: An fMRI study. Brain Research 1166: 92-102.

Semino, E. (2008). Metaphor in Discourse. Cambridge: Cambridge University Press.

Semino, E. (2009). Metaphor and situational motivation. Quaderns de Filologia. Estudis lingüístics. Vol. XIV: 221-233.

Sperber, D. and D. Wilson (1995). Relevance: Communication and Cognition, $2^{\text {nd }}$ edn. Oxford: Blackwell. 
Pre-proof version. Manuscript accepted for publication in Discourse \& Society.

Stanfield, R.A. and R.A. Zwaan (2001). The effect of implied orientation derived from verbal context on picture recognition. Psychological Science 12: 153-156.

Steen, G. (2008). The paradox of metaphor: Why we need a three-dimensional model of metaphor. Metaphor and Symbol 23: 213-241.

Steen, G.J. (2010). When is metaphor deliberate? In N.L. Johannesson, C. Alm-Arvius and D.C. Minugh (eds.), Selected Papers from the Stockholm 2008 Metaphor Festival. Stockholm: University of Stockholm. pp. 43--63.

Steen, G.J. (2011). The contemporary theory of metaphor - Now new and improved! Review of Cognitive Linguistics 9 (1): 26-64.

Steen, G.J., W.G. Reijnierse and C. Burgers (2014). When do natural language metaphors influence reasoning? A follow-up study to Thibodeau and Boroditsky (2013). PIOS ONE 9: e113536.

Subtirelu, N.C. and S.R. Gopavaram (2016). Crowdsourcing Critical Discourse Analysis: Using Amazon's Mechanical Turk to explore readers' uptake of comments about Language on RateMyProfessors.com. CADAAD 8 (1): 38-57.

Thibodeau, P.H. (2016). Extended metaphors are the home runs of persuasion: Don't fumble the phrase. Metaphor and Symbol 31 (2): 53-72.

Thibodeau, P.H and L. Boroditsky (2011). Metaphors we think with: The role of metaphor in reasoning. PLOS ONE 6 (2): e16782.

Thibodeau, P.H and L. Boroditsky (2013). Natural language metaphors covertly influence reasoning. PLOS ONE 8 (1): e52961.

Valenzuela, J. and C. Soriano (2007). Looking at metaphors: a picture-word priming task as a test for the existence of conceptual metaphor. Barcelona English Language and Literature Studies (BELLS) 16.

Van Leeuwen, T. (2007). Legitimation in discourse and communication. Discourse \& Communication 1 (1): 91-112.

Van Leeuwen, T. and R. Wodak (1999). Legitimizing immigration control: A discourse-historical analysis. Discourse Studies 10 (1): 83-118.

Walsh, P. (1990). Imagery as a heuristic in the comprehension of metaphorical analogies: Representation, Reasoning, Analogy and Decision-making. New York: John Wiley.

Wartenberg, C. and K. Holmqvist (2005). Daily newspaper layout - Designers' predictions of readers' visual behaviour: A cast study. Lund University Cognitive Studies 126.

Widdowson, H.G. (2004). Text, Context, Pretext: Critical Issues in Discourse Analysis. Oxford: Blackwell.

Zwaan, R.A., R.A. Stanfield and R.H. Yaxley (2002). Do language comprehenders routinely represent the shapes of objects? Psychological Science 13: 168-171.

Zillmann, D., R. Gibson and S.L. Sargent (1999). Effects of photographs in news-magazine reports on issue perception. Media Psychology 3: 301-324. 